\title{
Ulrike Krampl, Les secrets des faux sorciers. Police, magie et escroquerie à Paris au XVIII ${ }^{\mathrm{e}}$ siècle
}

Paris, Éditions de l'EHESS, coll. « En temps et lieux », 2012, 301 p.

\section{Constant Hamès}

\section{(2) OpenEdition}

\section{Journals}

Édition électronique

URL : http://journals.openedition.org/assr/24618

DOI : $10.4000 /$ assr. 24618

ISSN : $1777-5825$

Éditeur

Éditions de l'EHESS

Édition imprimée

Date de publication : 30 décembre 2012

Pagination : 221

ISSN : 0335-5985

Référence électronique

Constant Hamès, «Ulrike Krampl, Les secrets des faux sorciers. Police, magie et escroquerie à Paris au XVIII "e siècle », Archives de sciences sociales des religions [En ligne], 160 | octobre-décembre 2012 mis en ligne le 15 mars 2013, consulté le 21 septembre 2020. URL : http://journals.openedition.org/ assr/24618; DOI : https://doi.org/10.4000/assr.24618

Ce document a été généré automatiquement le 21 septembre 2020.

(c) Archives de sciences sociales des religions 


\section{Ulrike Krampl, Les secrets des faux sorciers. Police, magie et escroquerie à Paris au XVIII ${ }^{\mathrm{e}}$ siècle}

Paris, Éditions de l'EHESS, coll. « En temps et lieux », 2012, 301 p.

Constant Hamès

\section{RÉFÉRENCE}

Ulrike Krampl, Les secrets des faux sorciers. Police, magie et escroquerie à Paris au XVIII siècle, Paris, Éditions de l'EHESS, coll. « En temps et lieux », 2012, 301 p. 
1 Les études anthropologiques sur la magie, qu'elles portent sur le présent ou, comme ici, sur le passé parisien du $\mathrm{XVIII}^{\mathrm{e}}$ siècle, permettent toujours de révéler les tensions et les dynamiques à l'œuvre dans la société locale ou globale. Au point, peut-être, c'est une question que soulève la lecture de cet ouvrage, que la découverte des grands et des petits courants sociaux l'emporte sur la découverte de la magie elle-même. De quoi s'agit-il?

2 "Tribunaux" et "police " de la ville de Paris ont fourni, pour l'essentiel, le fonds documentaire $\mathrm{du}$ propos. Le cadre institutionnel qui a permis la récolte des informations («archives») découle de la réforme qui, à partir de 1667, centralise, amplifie et autonomise les pouvoirs de la

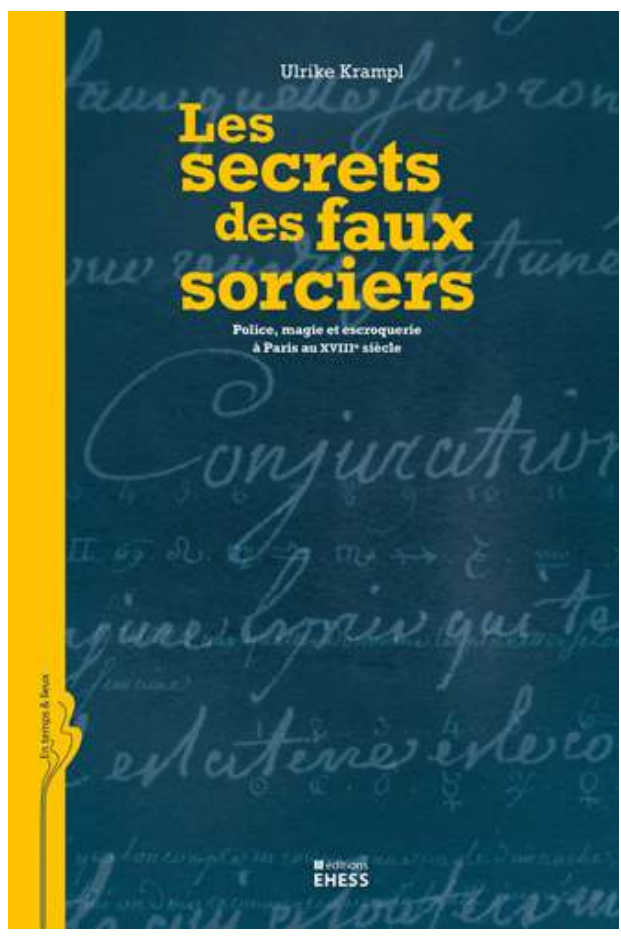
police, « renforçant la mainmise du roi sur la capitale ", " au détriment du Parlement et des élites municipales » (p.14). Idéologiquement aussi, le pouvoir de la police du roi se substitue au pouvoir spirituel de l'Église, marquant une forte rupture par rapport aux agissements inquisitoriaux des siècles précédents contre les crimes d'une sorcellerie aux pouvoirs diaboliques. Ceci ne veut pas dire que l'argumentation religieuse a disparu des procès contre la magie, mais que, par contre, elle n'est plus exercée directement par les autorités religieuses.

3 La série documentaire d'archives « est constituée de dossiers personnels, de papiers d'inspecteurs et de papiers administratifs, concernant, de 1692 à 1783, cent quatrevingt-dix-neuf cas qui impliquent quatre cent huit personnes, dont deux cent quarante et un hommes et cent soixante-sept femmes » (p. 21).

4 Le terme «faux sorciers » du titre et «escroquerie » du sous-titre attirent l'attention sur des perceptions et des définitions de la magie et de la sorcellerie élaborées au sein de la police, voire, "fabriquées » par elle (p.14). Les références ne sont en effet pas directement faites à la magie, «terme générique peu utilisé dans les sources ", mais à un mélange dépareillé de pratiques et de croyances: "conjuration des esprits et recherche de trésors, astrologie et divination ainsi que la fabrication et le débit de secrets pour l'amour, la chance et la santé, considérés comme "superstitions", mais susceptibles d'être associés au domaine de la sorcellerie ». Cette dernière devient un « crime imaginaire » incorporé au nouveau délit d'escroquerie.

5 Il serait sans doute illusoire, à travers l'analyse, même détaillée et précise, des cas recensés, d'espérer circonscrire un tant soit peu, sur le plan scientifique, les notions utilisées de magie et de sorcellerie. Cependant, on découvre que la toile de fond des croyances en œuvre s'inscrit régulièrement dans le registre des objets, rites et personnages du domaine religieux catholique. Le diable semble omniprésent, même s'il est devenu " imaginaire ». La notion de " péché » reste liée à celle de " trouble à l'ordre public» (p.96). La magie écrite puise abondamment dans les «textes religieux » qui peuvent se prêter à des usages magiques. Et, «parmi les hommes, les prêtres sont les 
dépositaires privilégiés de l'écrit magique ». Par contre, pour ce qui est des objectifs poursuivis par les "faux sorciers", ils rejoignent une sorte d'universalité planétaire des besoins et pulsions de l'humanité. "Se profile d'emblée un pôle fort autour de l'acquisition de richesses (trésors, transmutations) [...] la chasse au trésor, attestée depuis le Moyen Âge, connaît un essor sans précédent entre le XVII et le $\mathrm{XIX}^{\mathrm{e}}$ siècle " (p. 45). La fausse monnaie n'en est pas absente. «Dans l'ensemble, la magie des faux sorciers est une magie d'appropriation (acquisition de fortune, de bonheur), de protection [...] et de réparation [...] et non pas une magie agressive, de dépossession, voire d'atteinte physique » (p. 47). Cette dernière remarque signe le filtrage des affaires éventées par la police, car effectivement "l'histoire de la magie est d'abord une histoire des silences : les archives de la police ne renferment qu'une infime partie des magies qui se pratiquent dans Paris » (p. 63). On ajoutera, à titre simplement indicatif, que la magie et la divination ont, de tout temps, été l'apanage des cours des princes qui gouvernent, à l'écart du champ d'action de la police et des tribunaux. Que se passe-t-il donc de ce point de vue, à Versailles?

«Faire fortune », «principal objet que visent les moyens des faux sorciers» (p. 128), permet une analyse à la fois économique et sociale du monde parisien et de la façon dont les magiciens-escrocs s'y insèrent, notamment à travers les "marchés avec le diable ». Cela permet aussi, en corollaire, de réfléchir sur les paiements et contreparties exigés par le magicien. Et, très logiquement, se pose la question (aux échos évocateurs d'actualité) : faire de la magie un moyen de gagner sa vie peut-il être considéré comme un métier?

7 De fil en aiguille, l'ouvrage scrute Paris à travers les magiciens et leurs clientèles. Dans quels quartiers parisiens cela se passe-t-il de préférence? Quels sont les différents moments dans l'accomplissement d'un travail magique? Et, finalement, qu'est-ce que croire à la magie?

8 Doté d'une solide présentation des sources et de la bibliographie, augmenté d'une annexe sur les écrits trouvés en possession des accusés, l'ouvrage s'inscrit au carrefour de plusieurs registres : histoire de la magie, structures sociales entourant les pratiques magiques, évolution française des croyances magiques (siècle des Lumières!), histoire des institutions de la police, histoire des Parisiens, entre autres, et cela suscite l'intérêt. 